Article

\title{
Fish Passage Assessment of an Advanced Hydropower Turbine and Conventional Turbine Using Blade-Strike Modeling
}

\author{
Zhiqun Deng *, Thomas J. Carlson, Dennis D. Dauble and Gene R. Ploskey \\ Pacific Northwest National Laboratory, P.O. Box 999, Richland, WA 99352, USA; \\ E-Mails: thomas.carlson@pnl.gov (T.J.C); dennisdauble@ charter.net (D.D.D); \\ Gene.Ploskey@pnl.gov (G.R.P.) \\ * Author to whom correspondence should be addressed; E-Mail: zhiqun.deng@pnl.gov; \\ Tel.: +1-509-372-6120; Fax: +1-509-372-6089.
}

Received: 09 November 2010; in revised form: 19 December 2010 / Accepted: 27 December 2010 /

Published: 4 January 2011

\begin{abstract}
Hydropower is the largest renewable energy source in the world. However, in the Columbia and Snake River basins, several species of Pacific salmon and steelhead have been listed for protection under the Endangered Species Act due to significant declines of fish population. Dam operators and design engineers are thus faced with the task of making hydroelectric facilities more fish friendly through changes in hydro-turbine design and operation. Public Utility District No. 2 of Grant County, Washington, applied for relicensing from the U.S. Federal Energy Regulatory Commission to replace the 10 turbines at Wanapum Dam with advanced hydropower turbines that were designed to increase power generation and improve fish passage conditions. We applied both deterministic and stochastic blade-strike models to compare fish passage performance of the newly installed advanced turbine to an existing turbine. Modeled probabilities were compared to the results of a large-scale live-fish survival study and a Sensor Fish study under the same operational parameters. Overall, injury rates predicted by the deterministic model were higher than experimental rates of injury, while those predicted by the stochastic model were in close agreement with experimental results. Fish orientation at the time of entry into the plane of the leading edges of the turbine runner blades was an important factor contributing to uncertainty in modeled results. The advanced design turbine had slightly higher modeled injury rates than the existing turbine design; however, no statistical evidence suggested significant differences in blade-strike injuries between the two turbines, thus the hypothesis that direct fish survival rate through the advanced
\end{abstract}


hydropower turbine is equal to or higher than that for fish passing through the conventional turbine could not be rejected.

Keywords: advanced hydropower turbine; blade-strike modeling; fish-friendly turbine; dams

\section{Introduction}

Following many years of economic, engineering, and biological assessment, the Public Utility District No. 2 of Grant County (Grant PUD) applied in 2004 for relicensing of Wanapum Dam on the Columbia River in Washington State. The relicensing application to the U.S. Federal Energy Regulatory Commission (FERC) sought to replace the 10 Kaplan turbines at the dam with new ecologically friendly advanced hydropower turbines (AHTs). All existing turbines at Wanapum Dam were conventional Kaplan units consisting of a 7.24-m-diameter runner with five blades, 16 stay vanes, and 20 wicket gates. Depending on operating conditions, the turbine hub and blade tip gaps were significant and potential sources of fish injuries. In contrast to the conventional units, the new AHT design (Voith Siemens Hydro, Heidenheim, Germany) featured many elements included in the U.S. Department of Energy (DOE) AHT concept —improved operational performance [1,2], better passage conditions for fish, and increased power output, from 895 megawatts (MW) to 1,118 MW. The AHT design had a larger runner diameter of $7.75 \mathrm{~m}$. It had six blades and a spherical hub and discharge ring to virtually eliminate gaps at the hub and blade tips. The number of wicket gates was increased from 20 to 32 and the stay vanes were shaped to reduce turbulence.

The first of these AHTs was installed at Wanapum Dam Unit 8. It began operation in February 2005. The primary measure of biological performance testing for the new AHT was to compare estimates of fish passage and survival [3] using balloon-tag recapture methodology [4] and hydraulic conditions between the AHT and existing conventional turbine designs [5] and validate the hypothesis that the direct survival rate through the AHT is equal or higher than that for fish passing through the conventional turbine. The decision to proceed with replacement of the remaining nine turbines with the new AHTs depended on the results of these studies. In addition to the FERC relicensing studies funded by Grant PUD, the DOE Office of Energy Efficiency and Renewable Energy provided funding to conduct an expanded set of studies, including this study that would broaden the biological performance testing of the new AHT design.

Many numerical models have been developed to understand fish survival and behavior in reservoirs or rivers and streams (for example, [6]). However, the turbine environments are more complex. In addition, turbines have more hazardous features such as blade strike. Blade strike is the direct contact between a fish and the leading edge of a turbine blade. It is one of the major mechanisms that injure or kill fish [7-9]. Improvements in survival and reductions in the injury rate are being sought through changes in hydro-turbine design and operation [1].

Blade-strike modeling is an important and cost-effective approach to evaluate the biological performance of turbine design and operations. The first deterministic model for predicting probability of strike was proposed by Von Raben [10]. Other researchers expanded the model and investigated fish 
passage through turbine runners and associated injuries [11-16]. Deng et al. [17] introduced a stochastic blade-strike model and evaluated the validity of using blade-strike modeling as an estimate of the biological performance of large Kaplan turbines.

In this study, we applied both deterministic and stochastic blade-strike models to the newly installed AHT design and a conventional turbine. Modeled probabilities were compared to the results of a large-scale live-fish survival study [3] and a Sensor Fish study [5] under the same operational conditions.

\section{Method}

\subsection{Study Site}

Wanapum Dam is owned and operated by Grant PUD. The dam is located in central Washington on the Columbia River at river kilometer (rkm) 668 (Figure 1). Average river discharge at this location is approximately $3,400 \mathrm{~m}^{3} / \mathrm{s}$. The dam consists of a reinforced concrete powerhouse and spillway and a non-overflow earthfill section. Construction began in 1959, and power was first generated in 1963. The 305-m-long powerhouse contains 10 Kaplan turbine units. The spillway is $250 \mathrm{~m}$ long and has 12 Tainter-type radial arm floodgates.

Figure 1. Location of Wanapum Dam on the Columbia River at river km 668 in Central Washington State.

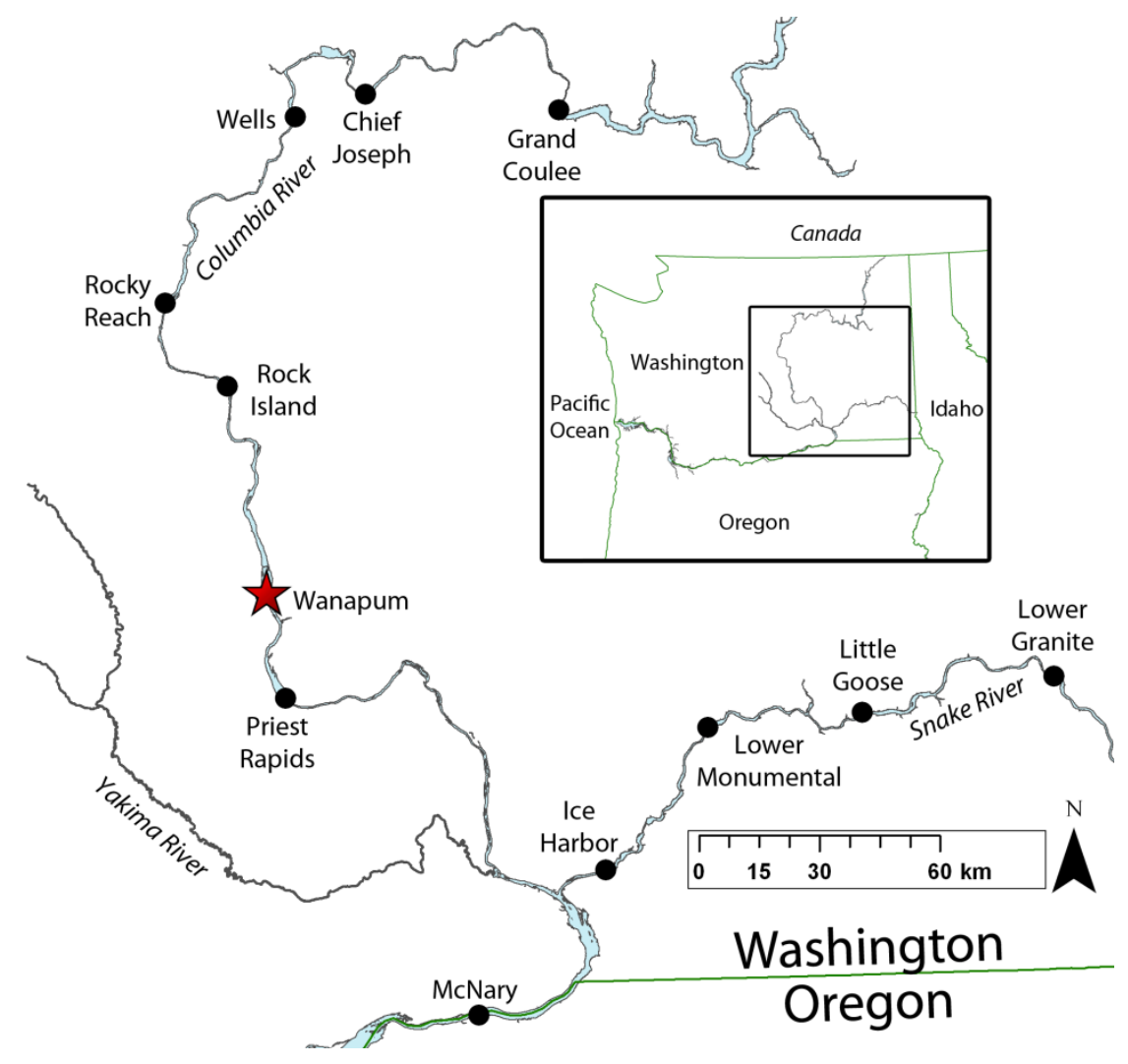

\subsection{Test Conditions}

Treatments consisted of combinations of two turbines (conventional turbine at Unit 9 and AHT at Unit 8 ), four turbine discharges $\left(255,311,425\right.$, and $\left.481 \mathrm{~m}^{3} / \mathrm{s}\right)$ for both turbines and one additional 
discharge $\left(524 \mathrm{~m}^{3} / \mathrm{s}\right.$ ) for the AHT design, three intake bays and two release elevations $(3 \mathrm{~m}$ and $9 \mathrm{~m}$ lower than the turbine ceiling, termed shallow and deep releases, respectively). Approximately 10,000 live test fish and 1,000 Sensor Fish device releases were conducted concurrently in two separate studies that were part of the FERC relicensing application: The live-fish study was conducted by Normandeau Associates to evaluate the injury and survival rates for the two turbine designs [3]. Sensor Fish devices [18] were deployed by the Pacific Northwest National Laboratory (PNNL) to characterize the exposure that fish experienced during turbine passage. These parameters included rates and severity of contacts (strikes by runner blades and collisions on stationary structure such as stay vanes), and exposure to severe turbulence, shear, and pressure changes [5].

\subsection{Blade-Strike Model}

In a previous study [17], we developed deterministic and stochastic blade-strike models for 1) the new minimum gap and original Kaplan runner turbines at the Bonneville Dam and 2) the 1:25-scale physical model of a McNary Dam turbine on the Columbia river. The performance of the numerical blade-strike models was then evaluated by comparing predictions of strike, injury, and mortality resulting with probabilities of blade strike on neutrally buoyant beads passing through the 1:25-scale physical turbine model. Predicted injury rates also were compared with actual rates of fish injury as determined in a balloon tag study of juvenile salmonid passage survival [19].

A fish will be struck by the blade if it does not pass through the plane of the leading edges of the runner blades within sweeps of two successive blades. The probability of strike is expressed as (see [17] for additional details):

$$
\mathrm{P}=\frac{\mathrm{t}}{\mathrm{t}_{\mathrm{cr}}}=\frac{1 \cdot \cos \theta \cdot n \cdot \frac{N}{60}}{\mathrm{~V}_{\text {axial }}}=\frac{1 \cdot \cos \theta \cdot n \cdot \frac{N}{60} \cdot \pi \cdot\left(R_{\text {tip }}^{2}-R_{\text {hub }}^{2}\right)}{\mathrm{Q}}
$$

where $t_{c r}$ is the critical passage time (the time between sweeps of two successive blades), $Q$ is the turbine discharge, 1 is the fish length in meters, $V_{\text {axial }}$ is the axial velocity, $n$ is the number of blades, $\mathrm{N}$ is the runner speed in revolutions per minute (rpm), $\mathrm{R}_{\text {tip }}$ is the radius of circle formed by the runner blade tip, $R_{\text {hub }}$ is the radius of circles formed by the runner hub, and $\theta$ is the angle between the absolute velocity and the axial velocity at a given fish passage location:

$$
\theta=90-\sin ^{-1} \frac{V_{\text {axial }}}{|V|}=90-\sin ^{-1} \frac{V_{\text {axial }}}{\sqrt{V_{\text {axial }}^{2}+V_{t}^{2}}}
$$

$V_{t}$ is the tangential velocity at the runner entrance and given by

$$
V_{t}=\frac{Q}{2 \pi \cdot H_{w g} \cdot R_{1} \cdot \tan \left(\theta_{w g t}\right)}
$$

where $\mathrm{H}_{\mathrm{wg}}$ is the wicket gate height, $\mathrm{R}_{1}$ is fish passage radius defined as the radius of a circle extending out along the blade from the runner hub to fish entrance, and $\theta_{\mathrm{wgt}}$ is the angle between the absolute velocity and tangential velocity at the downstream tip of wicket gate (Figure 2). 
Figure 2. Wicket opening, wicket gate angle, and $\theta_{\mathrm{wgt}}$.

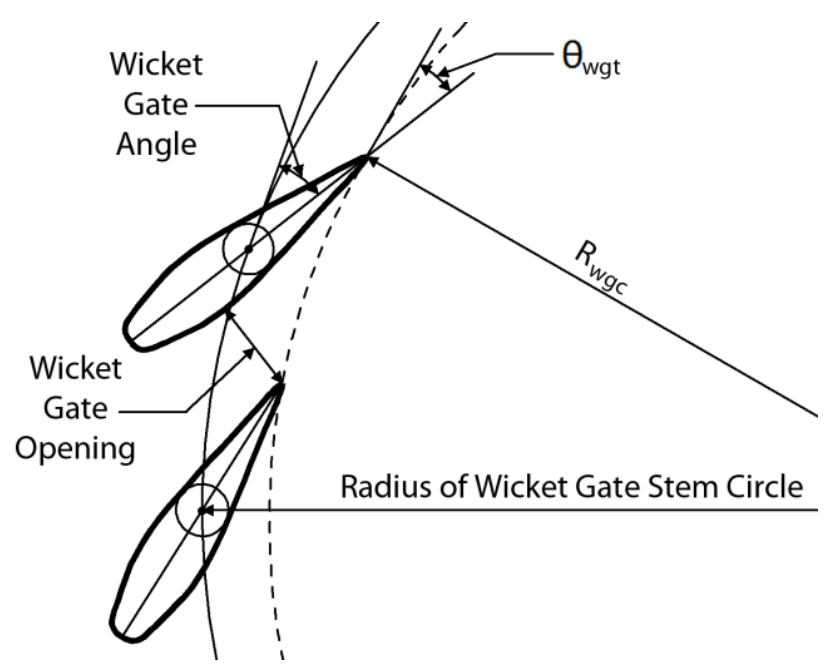

Wicket gate opening (WGO) is generally used to define wicket gate positions for turbine operation. We obtained the minimum distance between two adjacent gates using a linear search algorithm by computing all possible distances between two gates for any given wicket gate angle and developed a relationship for the wicket gate geometry over the operation range. For the AHT design,

$$
\theta_{w g t}=0.001631 \times W G O^{3}-0.01745 \times W G O^{2}+2.1657 \times W G O-2.5304
$$

and for the conventional turbine,

$$
\theta_{w g t}=0.000363 \times W G O^{3}-0.00331 \times W G O^{2}+1.4371 \times W G O-6.3281
$$

Von Raben [10] reported that not all fish struck by the blades were injured and introduced mutilation ratio as the percentage of injured fish among the fish struck by the blades. Turnpenny et al. [14] empirically developed a regression equation of mutilation ratio for different fish lengths:

$$
M R=0.15533 \ln (l)+0.0125
$$

where MR is mutilation ratio, ln is natural logarithm, and 1 is fish length (in centimeters), and injury rate is the product of MR and blade-strike probability.

The numerical deterministic and stochastic blade-strike models were run using the operational parameters of the FERC relicensing studies. The deterministic model assumed that fish were rigid bodies oriented perpendicular to the leading edge of the blade and predicted a single unique estimate for each combination of input values while the stochastic model analysis was performed using the Monte Carlo simulation method with 10,000 realizations. For both the Sensor Fish and live juvenile salmon, three variables were assigned distributions of possible values in the stochastic simulations. Discharge was assigned a uniform distribution ranging from the minimum to the maximum observed for each turbine at each turbine discharge treatment. We also applied distributions for two variables with the greatest uncertainty: fish-passage radius and fish length relative to the leading edge of the runner blade (see [17] for additional details). The distribution of fish-passage radius was assumed uniform between the runner hub and discharge ring radii so that the model predicted an average injury rate for fish equally distributed along the runner blades. The mean lengths of released fish and Sensor Fish were $169 \mathrm{~mm}$ (135 to $215 \mathrm{~mm}$ ) and $90.3 \mathrm{~mm}$, respectively, but the orientation of individuals 
passing the runner blades was unknown. To account for the uncertainty in test fish orientation during runner passage, we modeled several different normal and uniform distributions of relative fish length at the time of turbine runner entry. The model predictions were then compared with the injury rates of live fish and rate of collisions between Sensor Fish and runner blades.

\section{Results and Discussion}

\subsection{Deterministic Model Results}

The predictions of blade-strike probabilities using the deterministic model were compared to the Sensor Fish results [5] under the same operational parameters. For both turbines, Sensor Fish results were more variable than the predictions of the numerical model, especially for the conventional turbine. When the two release locations were combined, the trend was still evident for the average model prediction (Figure 3). This observation is consistent with the findings of our previous study [17] that one difference between blade strike model results and physical model observations was the higher variability between test conditions in physical model observations using neutrally buoyant particles.

Figure 3. Average of the predictions of blade strike by the deterministic model as a function of discharge and comparison with Sensor Fish results.

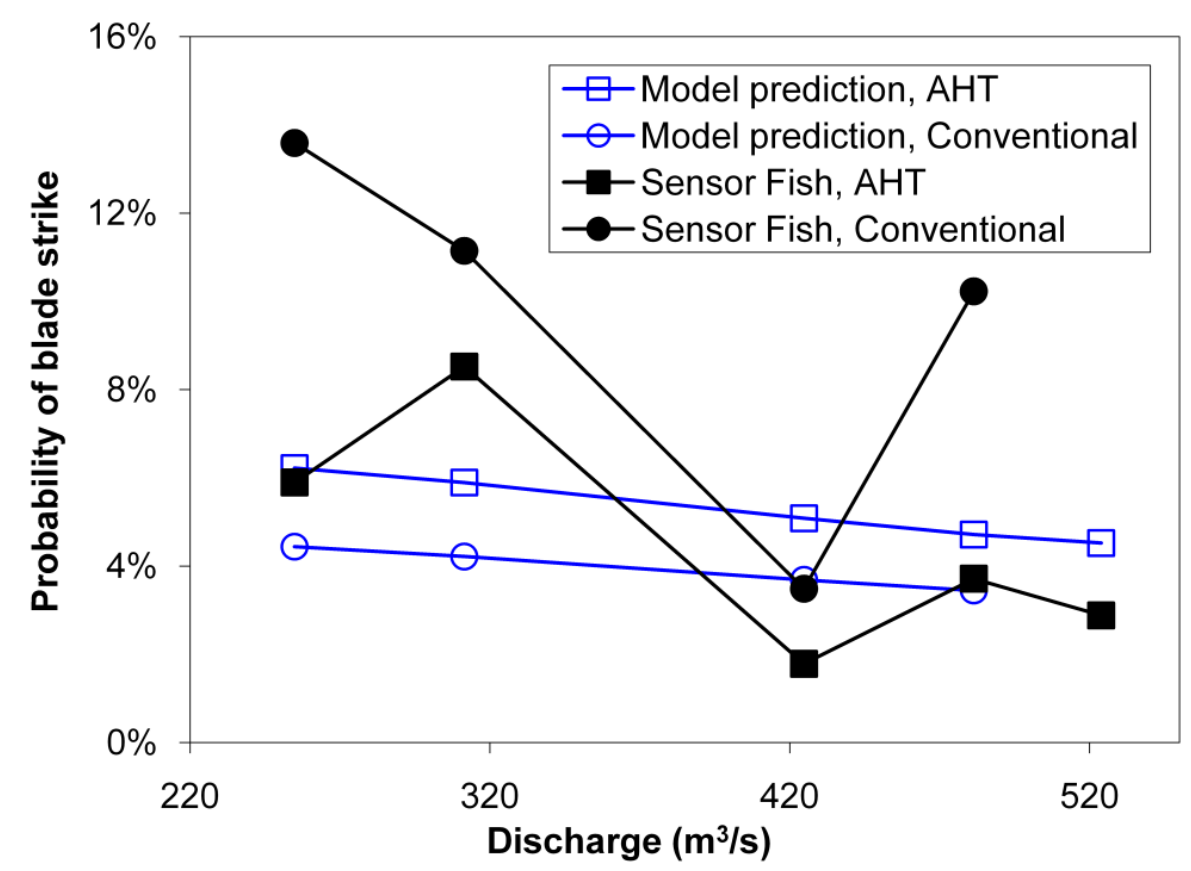

For both turbines, the predicted injury rates were higher than the rates of visible injury or mechanical injury reported by Normandeau et al. [3]. In addition, the high variability between the two fish release locations was not captured in the deterministic model. The average injury rates achieved by combining the two locations for each discharge were closer to the biological field test results, but in all case the model still over-predicted injury rate (Figure 4). 
Figure 4. Average of the predicted injury rate by the deterministic model as a function of discharge and comparison with injury types and injury rates for juvenile Chinook salmon.

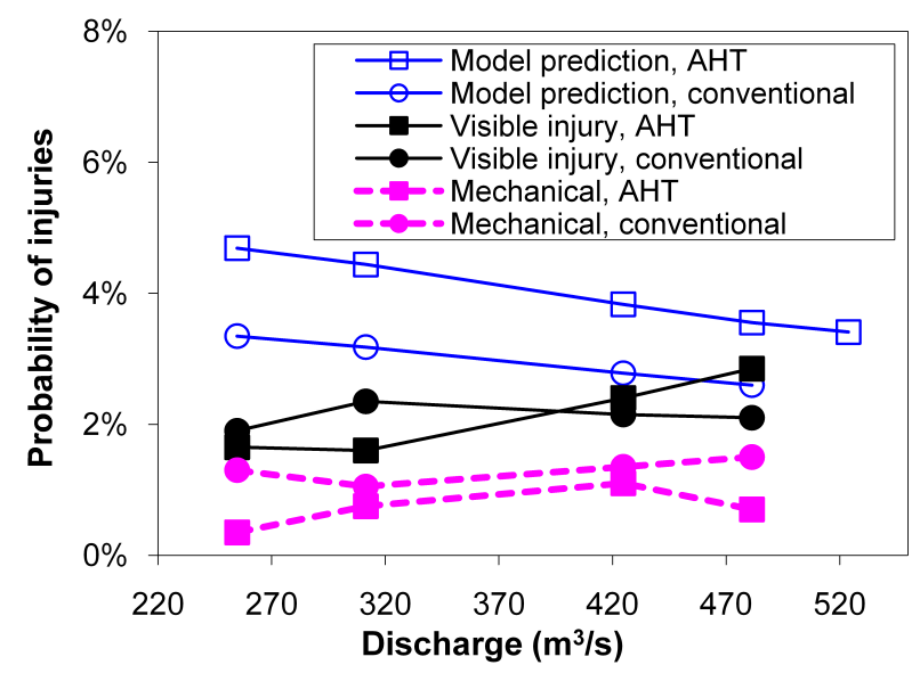

\subsection{Stochastic Model Results}

For both Sensor Fish and juvenile fish, the predicted results using the stochastic model were similar for the normal or uniform distribution of relative fish length, as long as the distribution covered any possible orientation or relative length at the instant of passage through the plane of the leading edges of the turbine runner blades. Therefore, only results using the normal distribution are presented. For both turbines, similar to the deterministic model, the high variability in the experimental results for different discharges was not present in the predicted blade-strike probabilities and the values of the modeled results were lower than those of the experimental results (Figure 5). The strike rates were highly correlated with the relative fish length and negatively correlated with discharges (Figure 6).

Figure 5. Predictions of blade strike by the stochastic model as a function of discharge and comparison with Sensor Fish results.

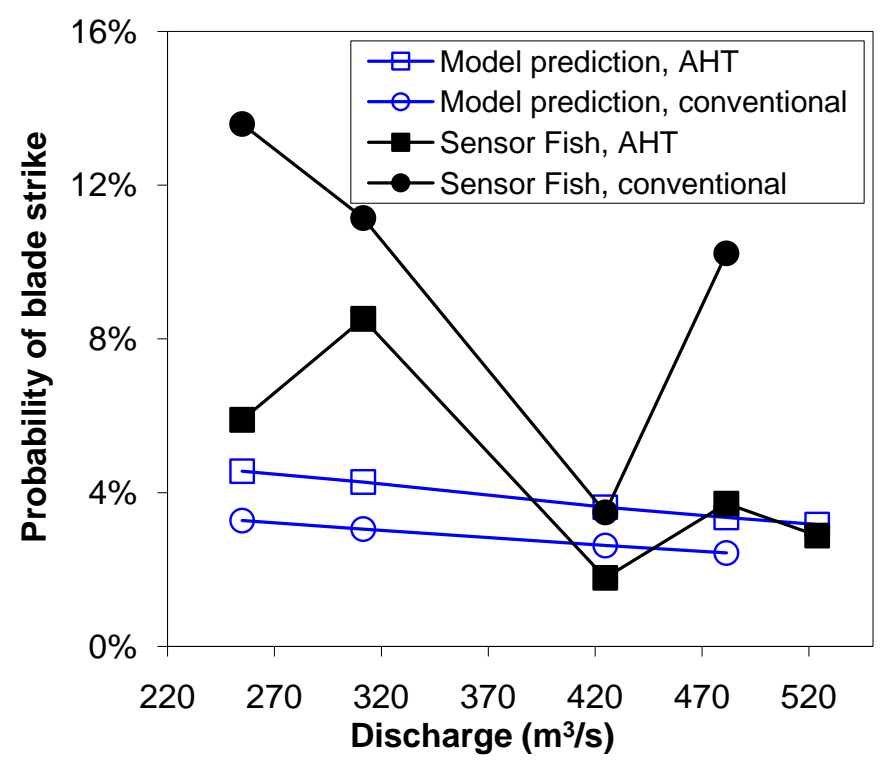


Figure 6. Distribution of assumed relative Sensor Fish length (left) and standardized regression coefficients (right) indicating the sensitivity of stochastic blade strike predictions to relative fish length, discharge, and fish-passage radius ( $\mathrm{R} \_$fish).
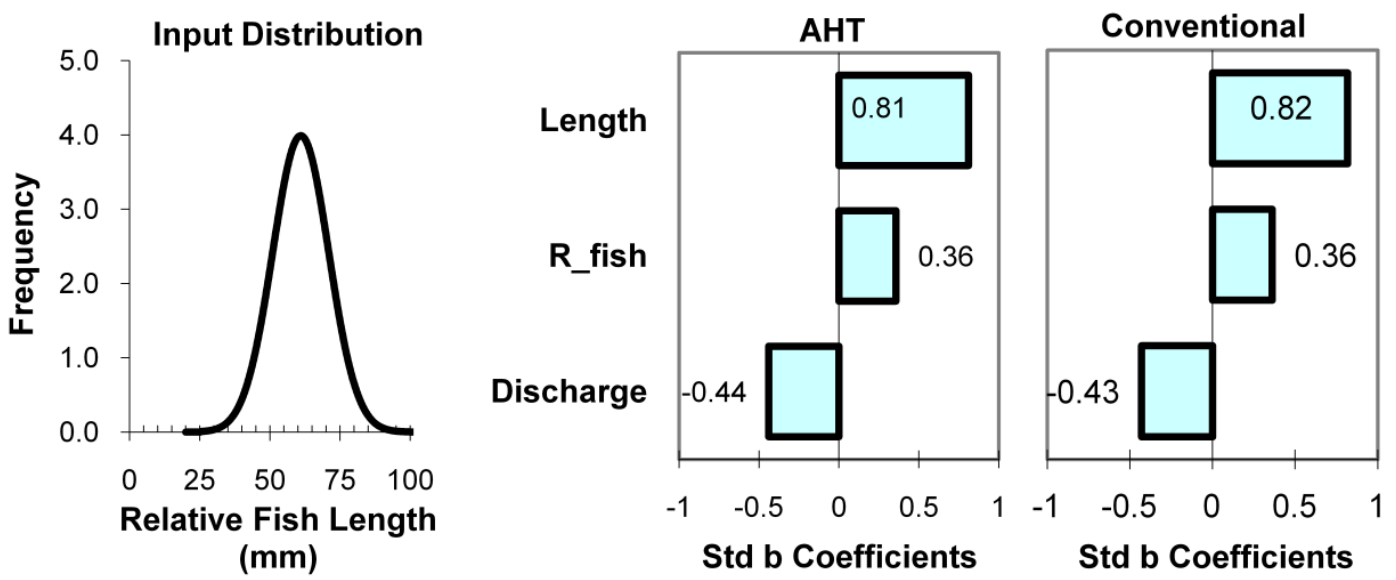

For all tested discharges of both turbines, the injury rates predicted by the stochastic model (Figure 7) were in close agreement with the rates of visible injury and higher than the mechanical injury rate of the experimental data. The close agreement can be better demonstrated when all test discharges were pooled (Figure 8). Although the injury rates for the conventional turbine were slightly lower than those for the new AHT, there is no statistically significant difference in blade-strike injury probabilities between the two turbines. In addition, the modeled injury rates are highly correlated with the relative fish length or the orientation of fish approaching the leading edge of the runner blades (Figure 9).

Figure 7. Predictions of blade strike injury rate by the stochastic model as a function of discharge and comparison with different injury types and injury rates for juvenile salmon.

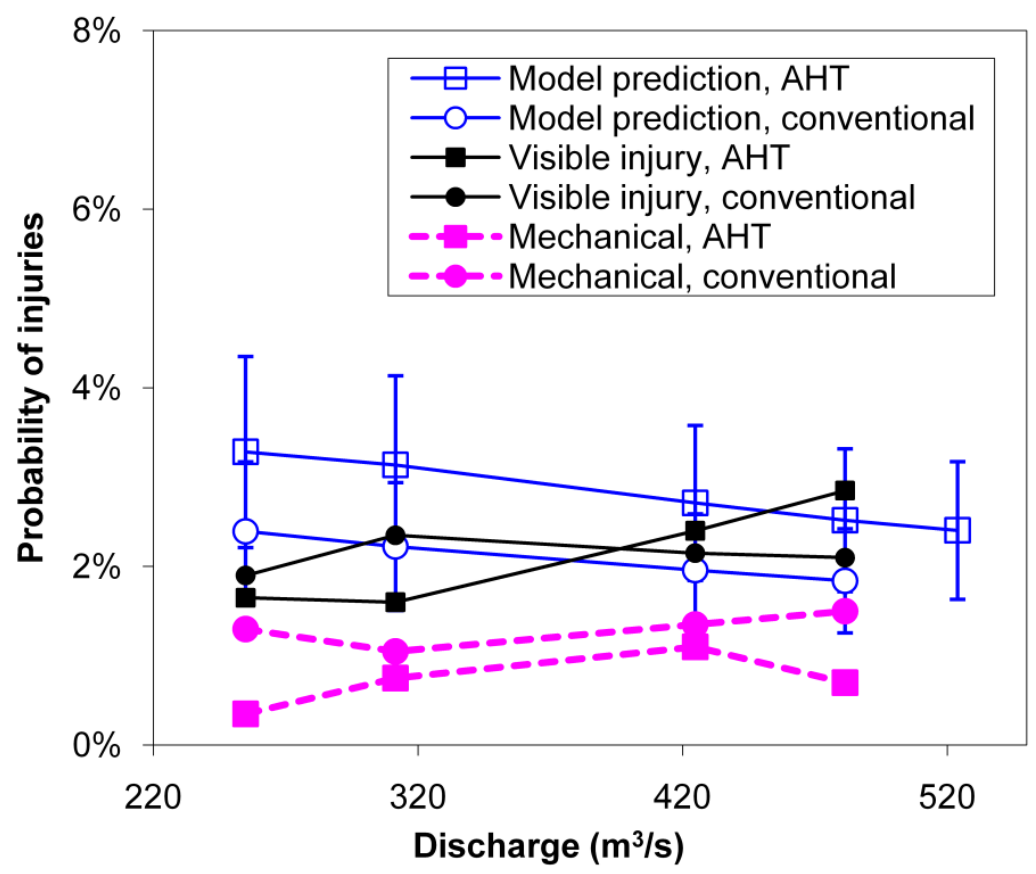


Figure 8. Comparing average injury rate predicted by the stochastic model with empirical estimates of visible injury, 48-hr mortality, shear, and mechanical injury.

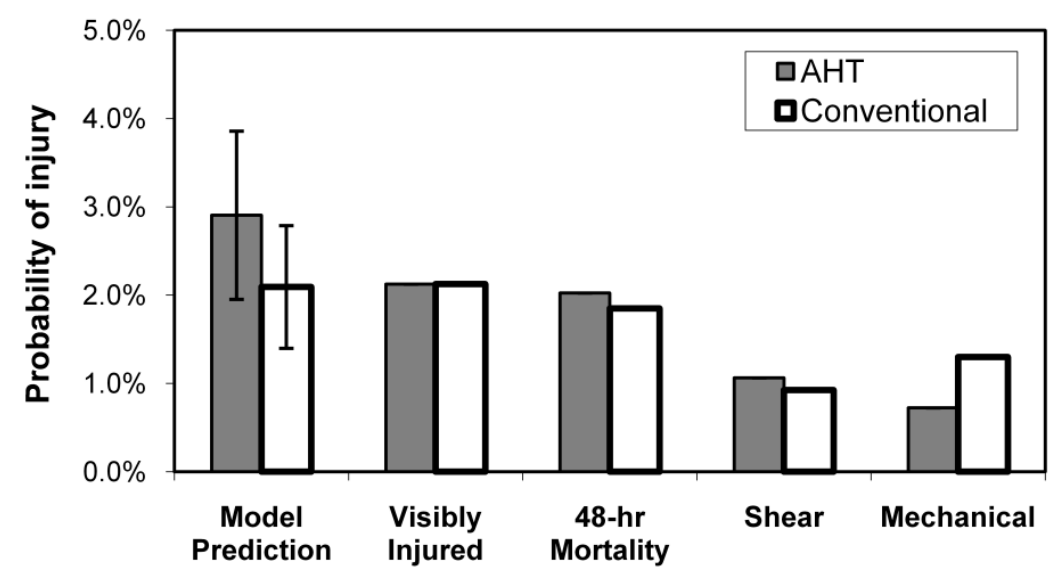

Figure 9. Assumed relative fish length distribution and regression coefficients indicating the sensitivity of the stochastic injury.
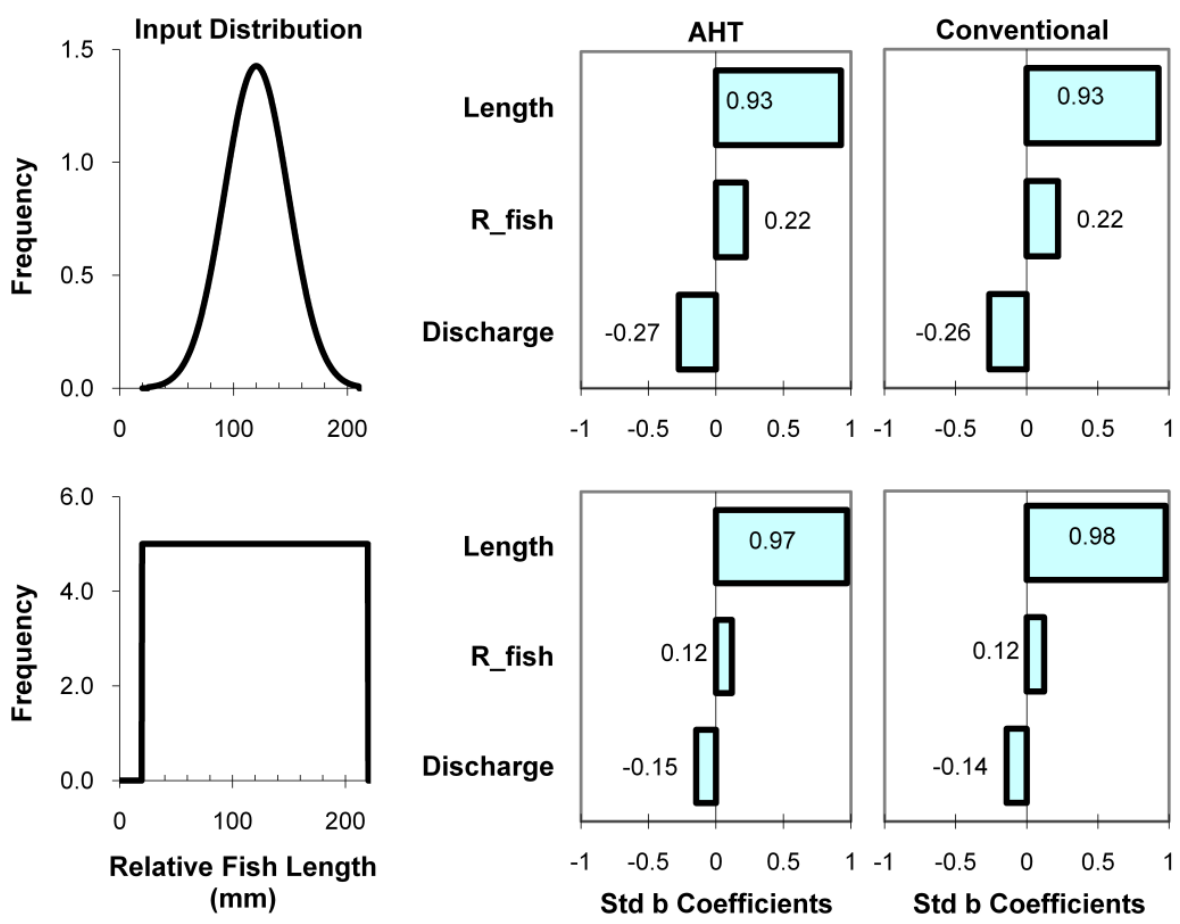

\section{Conclusions}

For both units, there was higher variability in the experimental results between different release locations or discharges than in the numerical results. This observation is consistent with the findings of our previous study in a 1:25-scale physical model of McNary Dam [17], which showed that the rate of severe contact of neutrally buoyant particles had higher variability between test conditions than the modeled results.

The modeled blade-strike probabilities for both units were lower than the experimental results using the Sensor Fish device. There are two possible explanations for the underprediction by the numerical models: 1) because the Sensor Fish has a rigid cylindrical body, any contact between the runner blades 
and any part of the Sensor Fish body would lead to a strike, which may not be true for a juvenile fish with a flexible body. 2) Because the flows around the runner are highly nonuniform and turbulent, Sensor Fish are not accelerated to the local flow velocity before they are carried by the flow to another location where the velocity is different. The Sensor Fish device would lag behind the local flows, leading to large slip velocity, tumbling of its body, and delay from the region before the second runner blade sweep.

Injury rates by the deterministic model were higher than the experimental rates of visible injury or mechanical injury. However, the injury rates predicted by the stochastic model were in close agreement with the rates of visible injury. Fish orientation at the time of entry into the plane of the leading edges of the turbine runner blades is one of the most significant factors and uncertainties in the models. The better agreement between experimental data and the stochastic model results from the fact that the stochastic blade-strike model considers the aspect of fish approaching the leading edges of a turbine runner's blades. The new AHT had slightly higher modeled injury rates than the original turbine, but there was no statistical evidence to suggest that there was significant difference in bladestrike injury probabilities between the two turbines, which is consistent with the experiment results using Sensor Fish and juvenile fish.

\section{Acknowledgements}

This study was funded by the U.S. Department of Energy (DOE) Office of Energy Efficiency and Renewable Energy Wind and Hydropower Technologies Program. Jim Ahlgrimm was the contracting officer for DOE, and Curt Dotson was the technical point of contact for Grant PUD. We also wish to thank Grant PUD and Normandeau Associates, Inc. for their help with this study. Andrea Currie and Tao Fu of PNNL provided comments and technical help preparing the manuscript. PNNL is owned by DOE and operated by Battelle Memorial Institute under Contract DE-AC05-76RL01830.

\section{References}

1. Odeh, M.; Sommers, G.; New design concepts for fish friendly turbines. Int. J. Hydropower Dams 2000, 73, 64-71.

2. Cada, G.F. The development of advanced hydroelectric turbines to improve fish passage survival. Fisheries 2001, 26, 14-23.

3. Normandeau Associates, Inc.; Skalski, J.R.; Townsend, R. Performance Evaluation of the New Advanced Hydropower Turbine (AHTS) at Wanapum Dam, Columbia River, Washington; Grant County PUD: Washington, DC, USA, 2005.

4. Mathur D.; Heisey, P.G.; Euston, E.T.; Skalski, J.R.; Hays, S. Turbine passage survival estimation for Chinook salmon smolts (Oncorhynchus tshawytscha) at a large dam on the Columbia River. Can. J. Fisheries Aquat. Sci. 1996, 53, 542-549.

5. Deng, Z.; Carlson, T.J.; Duncan, J.P.; Richmond, M.C.; Dauble, D.D. Use of an autonomous sensor to evaluate the biological performance of the advanced turbine at Wanapum Dam. J. Renewable Sustainable Energy 2010, 2, 053104, doi:10.1063/1.3501336. 
6. Wang Y.; Xia Z. Assessing spawning ground hydraulic suitability for Chinese sturgeon (Acipenser sinensis) from horizontal mean vorticity in Yangtze River. Ecol. Modell. 2009, 220, 1443-1448, doi: 10.1016/j.ecolmodel.2009.03.003.

7. Deng, Z.; Guensch, G.R.; McKinstry, C.A.; Mueller, R.P.; Dauble, D.D.; Richmond, M.C. Evaluation of fish-injury mechanisms during exposure to turbulent shear flow. Can. J. Fisheries Aquat. Sci. 2005, 62, 1513-1522.

8. Deng, Z.; Mueller, R.P.; Richmond, M.C.; Johnson, G.E. Injury and mortality of juvenile salmon entrained in a submerged jet entering still water. No. Am. J. Fish. Manage. 2010, 30, 623-628.

9. Cada, G.F.; Loar, J.; Garrison, L, Fisher, R., Jr.; Neitzel, D.A. Efforts to reduce mortality to hydroelectric turbine-passed fish: Locating and quantifying damaging shear stresses. J. Environ. Manage. 2006, 37, 898-906.

10. Von Raben, K. Regarding the problem of mutilations of fishes by hydraulic turbines. Die Wasserwirtschaft 1957, 4, 97-100.

11. Monten, E. Fish and Turbines: Fish Injuries during Passage through Power Station Turbines; Vattenfall: Stockholm, Sweden, 1985.

12. Solomon, D.J. Fish Passage through Tidal Energy Barrages; Technical Report for Energy Technology Support Unit: Harwell, UK, 1988; ETSU TID4056.

13. Turnpenny, A.W.H. Mechanisms of fish damage in low-head turbines: An experimental appraisal. In Fish Migration and Fish Bypasses; Jungwirth, M., Schmutz, S., Weiss, S., Eds.; Blackwell Publishing: Oxford, UK, 1998; pp. 300-314.

14. Turnpenny, A.W.H.; Clough, S.; Hanson, K.P.; Ramsay, R.; McEwan, D. Risk Assessment for Fish Passage Through Small, Low-Head Turbines; Technical Report for Energy Technology Support Unit: Harwell, UK, 2000; ETSUH/06/00054/REP.

15. Coutant, C.C.; Whitney, R.R. Fish behavior in relation to passage through hydropower turbines: A review. Trans. Am. Fisheries Soc. 2000, 129, 351-380.

16. Ferguson, J.W.; Ploskey, G.R.; Leonardsson, K.; Zabel, R.W.; Lundquist, H. Combining turbine blade-strike and life cycle models to assess mitigation strategies for fish passing dams. Can. J. Fisheries Aquat. Sci. 2008, 65, 1568-1585.

17. Deng, Z.Q.; Carlson, T.J.; Ploskey, G.R.; Richmond, M.C.; Dauble. D.D. Evaluation of blade-strike models for estimating the biological performance of Kaplan turbines. Ecol. Modell. 2007, 208, 165-176, doi:10.1016/j.ecolmodel.2007.05.019.

18. Deng, Z.; Carlson, T.J.; Duncan, J.P.; Richmond, M.C. Six-degree-of-freedom Sensor Fish design and instrumentation. Sensors 2007, 7, 3399-3415.

19. Normandeau Associates, Inc.; Skalski, J.R.; Mid-Columbia Consulting, Inc. Direct Survival and Condition of Juvenile Chinook Salmon Passed through an Existing and New Minimum Gap Runner Turbine at Bonneville Dam First Powerhouse, Columbia River; Report to U.S. Army Corps of Engineers: Portland, OR, USA, December 2000.

(C) 2011 by the authors; licensee MDPI, Basel, Switzerland. This article is an open access article distributed under the terms and conditions of the Creative Commons Attribution license (http://creativecommons.org/licenses/by/3.0/). 